\title{
Does intraoperative remifentanil infusion really make more postoperative pain?
}

\author{
Ji-Seon Son, and Seonghoon Ko \\ Department of Anesthesiology and Pain Medicine, Chonbuk National University Medical School, Jeonju, Korea
}

In the current issue of the Korean Journal of Anesthesiology, two articles demonstrate that N-methyl-D-aspartate (NMDA) receptor antagonists prevent remifentanil-induced hyperalgesia. Hong et al. [1] showed that continuous infusion of low dose ketamine decreased early postoperative pain score and analgesic requirement in patients with sevoflurane and remifentanil anesthesia. Lee et al. [2] also found that wound infiltration of magnesium sulfate decreased opioid consumption and reduced opioid-induced hyperalgesia (OIH). Ketamine is a non-competitive and magnesium is a physiologic NMDA receptor blocker. NMDA receptor blockers might prevent central sensitization by inhibiting activation of excitatory amino acids such as glutamate on NMDA receptors.

The administration of opioids is often related to the development of paradoxical and pathologic pain termed as $\mathrm{OIH}$ and tolerance. Tolerance is a pharmacologic concept which defined as a progressive decrease in response to a drug [3]. A variety of drugs, not a specific to the opioid family, can cause tolerance. Tolerance can be overcome by increasing dose of the drug. $\mathrm{OIH}$ is a paradoxical response to an opioid, whereby a patient receiving opioid for the treatment of pain might actually have an increase in pain perception to certain painful stimuli. OIH may complicate the clinical course of a patient who receives opioid treatment for pain control. The pronociception may occur in the same area as the underlying pain or away from the original site of the pain. The nature of pain often is associated with neuropathic pain such as hyperalgesia or allodynia. $\mathrm{OIH}$ is different from tolerance and it cannot be overcome by increasing dose of the drug because $\mathrm{OIH}$ is a pain sensitization of nerve system induced by the drug. Pain is aggravated with increased opioid dosage and improved by reducing or cessation of the drug. Therefore, $\mathrm{OIH}$ is clinical challenge to acute and chronic pain treatment.

Although there has been a controversy about its clinical implication, substantial evidence has been reported to support the development of OIH in experimental and clinical studies. There are several proposed mechanisms for OIH. Both central and peripheral sensitization to pain occurs in the nervous system. Central sensitization in the spinal cord involves the glutamate receptor, the NMDA receptor. The excitatory neurotransmitter plays a key role in the development of OIH. Spinal dynorphin levels were increased with continuous infusions of opioids and increased dynorphin levels lead to the release of spinal excitatory neuropeptides [4]. Neurons within the descending pathway in the spinal cord may facilitate spinal nocioceptive processing [5]. In cultured rat spinal neurons, remifentanil induce persistent increases in NMDA responses which is inducible by $\delta$-opioid receptor activation with a dynorphin agonist [6]. Gabapentin and pregabalin, which have a presynaptic effect on glutamate release, prevent $\mathrm{OIH}$ in rats and humans $[7,8]$. Also, these pro-nociceptive processes were facilitated in the spinal cord by increasing the synthesis of excitatory neuropeptides including 5-HT3, cholecystokinin, and substance P. Spinal dynorphin and facilitation of descending pathway in the spinal cord play important roles in OIH. Peripheral receptors also play a role in $\mathrm{OIH}$, with evidence that the transient receptor potential vanilloid receptor 1 (TRPV1) is important in the development of hyperalgesia [9,10]. A TRPV1

Corresponding author: Seonghoon Ko, M.D., Ph.D., Department of Anesthesiology and Pain Medicine, Chonbuk National University Medical School, 634-18, Keumam-dong, Jeonju 561-712, Korea. Tel: 82-63-250-1979, Fax: 82-63-250-1240, E-mail: shko@jbnu.ac.kr

(c) This is an open-access article distributed under the terms of the Creative Commons Attribution Non-Commercial License (http:// creativecommons.org/licenses/by-nc/3.0/), which permits unrestricted non-commercial use, distribution, and reproduction in any medium, provided the original work is properly cited. 
antagonist was found to reverse $\mathrm{OIH}$, along with increasing TRPV1 receptors in the dorsal root ganglia and increasing the response to capsaicin [11]. Although OIH is different from tolerance, OIH (sensitization) and opioid-induced tolerance may share common mechanisms in part, which mediated through activation of the central glutamatergic system [12]. Why some patients suffer from $\mathrm{OIH}$ while others on even larger doses of opioids do not? Which factors influence the incidence of OIH? Both opioid dose and duration of treatment seem to be important factors. Genetic factors are also likely to play a role in susceptibility to $\mathrm{OIH}$.

Remifentanil is a short-acting synthetic mu-opioid agonist. Intraoperative remifentanil infusion is increasing in clinical practice because remifentanil is rapidly degraded with a short half-life. Although the incidence of OIH and tolerance after opioid treatment of pain remains unknown, it seems to occur more frequently with the administration of the shortacting opioid remifentanil [13-15]. In clinical practice, patient receiving intraoperative remifentanil infusion may have more severe postoperative pain and increased analgesic requirement.

In recent study, Shin et al. [16] demonstrated $4 \mathrm{ng} / \mathrm{ml}$ of effect site concentration of remifentanil infusion increase postoperative cumulative morphine consumption compare to $1 \mathrm{ng} / \mathrm{ml}$ (38.6 vs $31.5 \mathrm{mg}$ ) after breast cancer surgery. Lee et al. [2] in the Korean Journal of Anesthesiology present that the time of first postoperative analgesic requirement is shorter in remifentanil infusion group (34 $\mathrm{min}$ ) than desflurane group (61 $\mathrm{min}$ ). Jo et al. [8] showed remifentanil infusion group (228 $\mu \mathrm{g})$ require more fentanyl dose than control group (134 $\mu \mathrm{g})$ for titration of pain in postanesthesia care unit. These studies report that remifentanil infusion groups have higher pain scores at postoperative period. The studies raise a question whether increased postoperative analgesic requirement and pain score could be associated with $\mathrm{OIH}$, tolerance or both.

If decreased or lack of efficacy of opioids in the postoperative period has been seen as a result of OIH, a major dilemma that anesthesiologists face. Because most anesthesiologists use opioids as the first line for postoperative pain control, it may be more prudent to use intraoperative remifentanil infusion. Although tolerance and OIH may share common mechanisms, it is challenging to distinguish between them since the treatment of each is quite different. OIH typically produces diffuse pain, less defined in quality, which extends to other areas from the preexisting pain. Schmidt et al. [17] studied patients with high dose $(0.4 \mu \mathrm{g} / \mathrm{kg} / \mathrm{min})$ or low dose $(0.1 \mu \mathrm{g} /$ $\mathrm{kg} / \mathrm{min}$ ) of remifentanil, and assessed postoperative pain at the surgical site and at other sites compared during preoperative baseline, at 30 and 90 min after cessation of remifentanil infusion. The patients who received high dose remifentanil anesthesia showed the development of hyperalgesia to painful pressure. In a double-blind randomized controlled trial of patients undergoing major abdominal surgery, results showed only transient higher pain scores in remifentanil group for up to $2 \mathrm{~h}$ after surgery [18]. Konopka and Wijhe [19] found that higher early postoperative pain score and subsequent greater demand of opioids after remifentanil-based anesthesia could be attributed to tolerance, and the greater requirement for opioids at a later recovery stage could be associated with OIH. Although there are many experimental and clinical studies on $\mathrm{OIH}$, further research is needed to define the clinical problem and neurobiological mechanisms including central and peripheral neural pathways. Furthermore, clinical studies need to be designed to differentiate between tolerance and $\mathrm{OIH}$ in order to develop clinical strategies to reduce $\mathrm{OIH}$ in the patients with intraoperative remifentanil in infusion.

\section{References}

1. Hong BH, Lee WY, Kim YH, Yoon SH, Lee WH. Effects of intraoperative low dose ketamine on remifentanil-induced hyperalgesia in gynecologic surgery with sevoflurane anesthesia. Korean J Anesthesiol 2011; 61: 238-43.

2. Lee C, Song YK, Jeong HM, Park SN. The effects of magnesium sulfate infiltration on perioperative opioid consumption and opioid-induced hyperalgesia in patients undergoing robot-assisted laparoscopic prostatectomy with remifentanil-based anesthesia. Korean J Anesthesiol 2011; 61: 244-50.

3. Chu LF, Angst MS, Clark D. Opioid-induced hyperalgesia in humans: molecular mechanisms and clinical considerations. Clin J Pain 2008; 24: 479-96.

4. Gardell LR, Wang R, Burgess SE, Ossipov MH, Vanderah TW, Malan TP Jr, et al. Sustained morphine exposure induces a spinal dynorphin-dependent enhancement of excitatory transmitter release from primary afferent fibers. J Neurosci 2002; 22: 6747-55.

5. Morgan MM, Heinricher MM, Fields HL. Circuitry linking opioidsensitive nociceptive modulatory systems in periaqueductal gray and spinal cord with rostral ventromedial medulla. Neuroscience 1992; 47: 863-71.

6. Zhao M, Joo DT. Enhancement of spinal N-methyl-D-aspartate receptor function by remifentanil action at delta-opioid receptors as a mechanism for acute opioid-induced hyperalgesia or tolerance. Anesthesiology 2008; 109: 308-17.

7. Van Elstraete AC, Sitbon P, Mazoit JX, Benhamou D. Gabapentin prevents delayed and long-lasting hyperalgesia induced by fentanyl in rats. Anesthesiology 2008; 108: 484-94.

8. Jo HR, Chae YK, Kim YH, Chai HS, Lee WK, Choi SS, et al. Remifentanil-induced pronociceptive effect and its prevention with pregabalin. Korean J Anesthesiol 2011; 60: 198-204.

9. Amadesi S, Nie J, Vergnolle N, Cottrell GS, Grady EF, Trevisani $\mathrm{M}$, et al. Protease-activated receptor 2 sensitizes the capsaicin receptor transient receptor potential vanilloid receptor 1 to induce hyperalgesia. J Neurosci 2004; 24: 4300-12.

10. Kawamata T, Ji W, Yamamoto J, Niiyama Y, Furuse S, Namiki A. Contribution of transient receptor potential vanilloid subfamily 1 
to endothelin-1-induced thermal hyperalgesia. Neuroscience 2008; 154: 1067-76.

11. Tekus V, Bolcskei K, Kis-Varga A, Dezsi L, Szentirmay E, Visegrady A, et al. Effect of transient receptor potential vanilloid 1 (TRPV1) receptor antagonist compounds SB705498, BCTC and AMG9810 in rat models of thermal hyperalgesia measured with an increasingtemperature water bath. Eur J Pharmacol 2010; 641: 135-41.

12. Mao J, Price DD, Mayer DJ. Mechanisms of hyperalgesia and morphine tolerance: a current view of their possible interactions. Pain 1995; 62: 259-74.

13. Hood DD, Curry R, Eisenach JC. Intravenous remifentanil produces withdrawal hyperalgesia in volunteers with capsaicin-induced hyperalgesia. Anesth Analg 2003; 97: 810-5.

14. Guignard B, Bossard AE, Coste C, Sessler DI, Lebrault C, Alfonsi P, et al. Acute opioid tolerance: intraoperative remifentanil increases postoperative pain and morphine requirement. Anesthesiology 2000; 93: 409-17.
15. Angst MS, Koppert W, Pahl I, Clark DJ, Schmelz M. Short-term infusion of the mu-opioid agonist remifentanil in humans causes hyperalgesia during withdrawal. Pain 2003; 106: 49-57.

16. Shin SW, Cho AR, Lee HJ, Kim HJ, Byeon GJ, Yoon JW, et al. Maintenance anaesthetics during remifentanil-based anaesthesia might affect postoperative pain control after breast cancer surgery. Br J Anaesth 2010; 105: 661-7.

17. Schmidt S, Bethge C, Forster MH, Schafer M. Enhanced postoperative sensitivity to painful pressure stimulation after intraoperative high dose remifentanil in patients without significant surgical site pain. Clin J Pain 2007; 23: 605-11.

18. Hansen EG, Duedahl TH, Romsing J, Hilsted KL, Dahl JB. Intraoperative remifentanil might influence pain levels in the immediate post-operative period after major abdominal surgery. Acta Anaesthesiol Scand 2005; 49: 1464-70.

19. Konopka KH, van Wijhe M. Opioid-induced hyperalgesia: pain hurts? Br J Anaesth 2010; 105: 555-7. 